\title{
Estudio comparado de la diligencia debida reforzada como parámetro de medición de la respuesta institucional a la violencia de género
}

Comparative study about reinforced due diligence as a measurement parameter of the institutional response to gender violence

\author{
SERGIO DE LA HERRÁN RUIZ-MATEOS \\ Investigador predoctoral FPU de Derecho Penal \\ Universidad de Cádiz (España)
}

sergio.delaherran@uca.es

https://orcid.org/0000-0002-2681-8631

\begin{abstract}
Resumen: El obligado compromiso de los Estados y las instituciones en la lucha contra la violencia de género y la protección a las víctimas está fuera de toda duda. Los avances normativos en esta materia han incorporado expresas referencias a la sujeción preceptiva al seguimiento, prevención y represión de actos de agresión contra las mujeres. En este sentido, América y Europa han alcanzado un desarrollo normativo y jurisprudencial nada desdeñable. Tanto la Corte Interamericana de Derechos Humanos como el Tribunal Europeo de Derechos han logrado dar pasos importantes en esta línea y han desarrollado el parámetro de diligencia debida reforzada en violencia de género para valorar la responsabilidad estatal en el cumplimiento de sus obligaciones de prevención, represión y reparación.
\end{abstract}

Abstract: The obligatory commitment of the States and the institutions in the fight against the gender violence and the protection of victims is beyond any doubt. The normative advances in this matter have incorporated express references to the mandatory subjection to the monitoring, prevention and repression of acts of sexist aggression against women. In this sense, Europe and America have reached a not inconsiderable normative and jurisprudential development. Both the

Cómo citar este trabajo: DE LA HERRÁN RUIZ-MATEOS, Sergio, "Estudio comparado de la diligencia debida reforzada como parámetro de medición de la respuesta institucional a la violencia de género", Revista de Estudios Jurídicos y Criminológicos, n. ${ }^{\circ} 4$, Universidad de Cádiz, 2021, pp. 25-48, DOI: https://doi.org/10.25267/REJUCRIM.2021.i.4.03 
InterAmerican Court of Human Rights and the European Court of Rights have managed to take important steps in this line and have developed the parameter of reinforced due diligence in gender violence to assess state responsibility in complying with its obligations of prevention, repression, and reparation.

Palabras claves: violencia contra la mujer, derechos humanos, diligencia debida reforzada, Tribunal Europeo de Derechos Humanos, Corte Interamericana de Derechos Humanos.

Keywords: violence against women, human rights, enhanced due diligence, Europa, America.

Sumario: 1. APROXIMACIÓN. 2. NORMATIVIDAD E INTERÉS ESTATAL EN LA VIOLENCIA CONTRA LA MUJER. 3. LA DILIGENCIA DEBIDA REFORZADA COMO PARÁMETRO DE MEDICIÓN DE LA RESPUESTA INSTITUCIONAL A LA VIOLENCIA CONTRA LA MUJER. 3.1. El estándar de diligencia debida en el marco de los derechos humanos. 3.2. Experiencia americana: la contribución de la Corte Interamericana de Derechos Humanos. 3.3. Experiencia europea: referencias al Tribunal Europeo de Derechos Humanos. 3.4. Recepción española. 4. REFLEXIONES FINALES. 5. BIBLIOGRAFÍA.

\section{APROXIMACIÓN}

La mujer ha sido la gran olvidada en la edificación del orden jurídico internacional de los derechos humanos ${ }^{1}$, al menos desde una perspectiva occidental. Pese a la creciente preocupación por la indemnidad de los derechos humanos a partir de la mitad del siglo $\mathrm{XX}$, no todas las representaciones e identidades de la ciudadanía han evolucionado al mismo ritmo, bien por la invisibilización de esas realidades o bien por su normalización social. Esta ha sido la experiencia en todo lo relativo al reconocimiento de derechos a las mujeres y a la violencia que sufren por razón del género. Ha tenido que ser la crudeza desprendida por un criterio tan aséptico como la estadística que cuantifica el número de mujeres asesinadas y maltratadas la que, junto al movimiento feminista, ha provocado a un cambio de tendencia ${ }^{2}$. Los datos que se fueron revelando pusieron pronto de manifiesto que este fenómeno, además de acrecentarse cuantitativa y cualitativamente, estaba arraigado a las estructurales sociales y culturales del mundo, lo que obligó a que la respuesta institucional tuviese una clara vocación universal, es decir, que fuese válida desde un prisma internacional para quedar alineada con la importancia que merecen los derechos humanos, o, mejor dicho: incrementándola. A este propósito se trae el objeto de estudio de este trabajo como es el análisis de la diligencia debida como parámetro de medición de la respuesta institucional a las violaciones de derechos humanos por parte de la Corte Interamericana de Derechos Humanos (en adelante, CIDH) y el Tribunal Europeo de Derechos Humanos (en adelante, TEDH). No obstante, a este criterio, común a la

\footnotetext{
${ }^{1}$ FERNÁNDEZ, E., Igualdad y Derechos Humanos, Tecnos, Madrid, 2003, pág. 30.

${ }^{2}$ Sobre este punto léanse las obras de EDWARS, A., Violence against women under international Human Rights Law, Cambriange University Press, 2011, o de VALERA, N., Feminismos para principiantes, Peguin Random, Barcelona, 2019.
} 
evaluación de la actuación de los Estados en el cuidado de los derechos humanos, se le añade en violencia de género un plus de exigencia que ha sido definido por su carácter "reforzado". La violencia de género pasa a ser abordada como un problema concerniente a los derechos humanos que necesita de un especial cuidado en su tratamiento. Esto último ha venido acompañado de la superación de aquella praxis jurídica por la que los Estados recurrían a instrumentos normativos frágiles, sin fuerza vinculante y de naturaleza recomendatoria para canalizar y despachar sus obligaciones internacionales. La principal consecuencia que traía esta práctica era que la calidad de la atención legislativa, policial y judicial a las víctimas de violencia de género se dejaba en manos de la voluntad política de cada Estado. Por fortuna, en la actualidad se está en disposición de un acervo normativo que ha tipificado deberes expresos que no dejan alternativa a los Estados, siendo ya conocidas diversas resoluciones que condenan a entidades estatales por la infracción de esos deberes impuestos por la diligencia debida reforzada en violencia contra la mujer. No es menos cierto, por el contrario, que todavía dichas resoluciones se topan con grandes obstáculos en fase ejecutiva.

En este orden de ideas, es indiscutible que, al día de hoy, el fenómeno de la violencia de género, entendido este en un sentido amplio como cualquier acto de violencia física, psíquica, sexual o económica producida contra una mujer tanto en el ámbito familiar como fuera de él, constituye uno de los grandes retos para las democracias actuales, pues con él y, en ocasiones, la inacción de lo institucional, se perpetúa una violación sistémica de derechos humanos ${ }^{3}$. En consecuencia, los Estados, más allá de los legítimos postulados ideológicos de cada Gobierno, quedan así corresponsabilizados normativamente con la violencia de género, tanto desde el punto de vista de la correcta adopción y transposición de la normativa internacional vigente, como en el diseño de las reformas necesarias para que las mujeres disfruten una vida libre de violencias y, en su caso, con mejoras en los sistemas de prevención, detección, sanción y reparación. No obstante, con carácter previo al estudio del contenido de la diligencia debida reforzada por violencia de género resulta ineludible llevar a cabo una aproximación al armazón normativo que ha posibilitado el establecimiento de criterios válidos para, inclusive, exigir responsabilidad a los Estados en supuestos de omisión o negligencia en el cumplimiento de sus deberes para con este modo de criminalidad.

\section{NORMATIVIDAD E INTERÉS ESTATAL EN LA VIOLENCIA CONTRA LA MUJER}

El compromiso por parte del poder institucional de los Estados con las políticas de igualdad y la erradicación de la discriminación por razón de género ha experimentado un loable incremento en las últimas décadas. Las distintas legislaciones nacionales han comenzado a incorporar normas relacionadas con la lucha contra la desigualdad y la violencia de género. Mas alcanzar esto no ha sido tarea fácil. Si bien hoy puede afirmarse que es la integración en organizaciones internacionales de corte planetaria, americana o

\footnotetext{
${ }^{3}$ En este sentido, MESTRE CHUST, J.V., Los derechos humanos, UOC, Barcelona, 2007, págs. 65 y ss.
} 
europea la que exige esta labor desde su acervo normativo, en tiempos pretéritos esto quedaba abandonado al albur del voluntarismo de cada Estado y, en consecuencia, condicionado a la posición política de quien ostentaba el poder gubernamental en cada momento.

Así, en la esfera internacional, la Organización de las Naciones Unidas (en adelante, ONU) desde un primer momento con la Declaración Universal de Derechos Humanos de 1948 instituyó la igualdad y la no discriminación por razón de sexo como uno de sus principios ineludibles. Este fue el comienzo de lo que luego pasó a ser la Comisión de la Condición Jurídica y Social de la Mujer (1946), creada para llevar a cabo balances sobre la situación de la mujer en el mundo y la promoción de sus derechos, y la Convención sobre la eliminación de todas las formas de discriminación sobre la mujer (1981), más conocida por la siglas 'CEDAW', que además compuso un Comité para la recepción de denuncias por violación de los derechos reconocidos en la CEDAW y la supervisión del progreso de los Estados parte en la labor de implementación de las recomendaciones, de las que interesa especialmente la Recomendación General núm. 19 (1992), posteriormente actualizada por la núm. $35(2017)^{4}$. Toda la contribución normativa realizada por este organismo se ha encontrado con lo que la doctrina constitucionalista e internacionalista ha valorado como su mayor obstáculo, como es el valor jurídico y la débil fuerza vinculante de sus instrumentos ${ }^{5}$, en especial en lo que se refiere al derecho a la restitución en fase ejecutiva. Sin embargo, no fue hasta la aprobación de la Declaración sobre la eliminación de la violencia contra la mujer (1993) que no se estimó el fenómeno de la violencia contra la mujer como una forma de transgredir los derechos humanos ${ }^{6}$. Este acontecimiento vino acompañado de la normativización de obligaciones internacionales que exigían a los Estados poner en efecto medidas encaminadas a contrarrestar la violencia contra la mujer. Este es el principal antecedente de lo que posteriormente ha dado lugar al estándar de diligencia debida como parámetro de control y medición de la actuación de los Estados en la protección, prevención y represión de actos de violencia contra la mujer. Dos años después de la aprobación de esta Declaración, se celebró la IV Conferencia Internacional sobre la Mujer de Beijing, que, en opinión de

\footnotetext{
${ }^{4}$ Entre otras muchas cosas, esta recomendación identificó la violencia de género como una discriminación por razón de género que afecta o anula el disfrute de los derechos humanos y libertades fundamentales de las mujeres (Recomendación núm. 19), así como ha advertido a los Estados que es posible atribuirles responsabilidad por omisiones en la adopción de las medidas necesarias para impedir la violación de los derechos reconocidos o en las labores de investigación, prevención y sanción de actos de violencia (Recomendación núm. 35).

5 Así, CARRILlo SAlCEDO, J.A., Dignidad frente a barbarie. La Declaración Universal de los Derechos Humanos cincuenta años después, Trotta, Madrid, 1999, págs. 88-95 y 145.

${ }^{6}$ Discrepante en este punto EDWARS que objeta la titubeante inclusión de la violencia de género en el contexto internacional de violaciones de Derechos Humanos. La autora afirma la necesidad de que la violencia de género se estudie desde la perspectiva de universalidad demandada por los derechos humanos y denuncia que en esa tarea las mujeres han sido las grandes olvidadas (Violence against women under International Human Rights Law, op. cit., 2011, pág. 7, 22 y ss.).
} 
ACALE SÁNCHEZ ${ }^{7}$, supuso la apuesta decidida y definitiva de Naciones Unidas por la lucha contra la violencia machista ${ }^{8}$.

Un estudio que trate la violencia de género desde la perspectiva de los derechos humanos debe mencionar los trabajos desarrollados en el seno de la Organización de los Estados Americanos (en adelante, OEA), en concreto los elaborados por la Comisión Interamericana de Mujeres, que fue pionera en la adopción de un tratado de carácter vinculante en el reconocimiento de la violencia contra las mujeres como una grave violación de derechos humanos y en la confección de un sistema de obligaciones para los Estados dirigidos a garantizar y actuar con diligencia debida en la defensa de los derechos reconocidos en el Tratado con el objetivo de garantizar una vida libre de violencia a las mujeres. Este objetivo se alcanzó finalmente en 1994 con la Convención Interamericana para prevenir, sancionar y erradicar la violencia contra la mujer (en adelante, Convenio de Belém do Pará). En este sentido, fue la CIDH el organismo jurisdiccional que tuvo antes a su disposición un compendio normativo útil para el desarrollo del parámetro de la diligencia debida en violencia de género ${ }^{9}$.

En el espacio europeo, el compromiso con los derechos humanos y con la igualdad se hallan inscritas en las raíces de la formación de Europa. Así, en el ámbito del Consejo de Europa, el Convenio Europeo de Derechos Humanos de 1950 (en adelante, CEDH), junto con los protocolos 7 (1984) y 12 (2008), reconoce como derecho de primer orden el de la igualdad y proscribe toda discriminación por razón sexo - hubiese sido más acertado la mención al "género" y no al sexo. No obstante, el punto de inflexión llegó con la aprobación del Convenio del Consejo de Europa sobre prevención y lucha contra la violencia contra la mujer en 2011 (en adelante, Convenio de Estambul. Este texto, de carácter vinculante, ha significado un antes y un después en la forma en que los Estados afrontan la lucha contra la violencia de género, pues tiene la virtualidad de hacer frente tanto a la violencia de género como a la violencia doméstica desde una misma óptica, es decir, no como formas diferenciadas de violencia, sino como distintas tipologías que forman parte de un amplio elenco de manifestaciones y perfiles que puede adoptar la violencia contra la mujer ${ }^{10}$. Hasta este momento, en realidad, no se había hecho frente

\footnotetext{
${ }^{7}$ Vid., ACALE SÁNCHEZ, M., La discriminación hacia la mujer por razón de género en el Código penal, Reus, Madrid, 2006, págs. 64 y ss.

${ }^{8}$ Los trabajos realizados en el marco de la Conferencia Internacional sobre la Mujer de Beijing han resultado de suma importancia en España. Tanto es así que los trabajos en la elaboración de la Ley Orgánica 1/2004, de 28 de diciembre, de Medidas de Protección Integral contra la Violencia de Género, se inspiraran en aquellos, aunque luego finalmente quedara restringido al ámbito familiar. Ampliamente, ídem.
}

${ }^{9}$ Se recomienda la lectura de la Guía para la aplicación de la Convención Interamericana para prevenir, sancionar y erradicar la violencia contra la mujer elaborada por el Mecanismos de Seguimiento de la Convención de Belém do Pará (MESECVI) que detalla los orígenes y el contenido de esta. Disponible en: http://www.oas.org/es/mesecvi/biblioteca.asp\#herramientas. Asimismo, FERIA-TINTA, M., "Primer caso internacional sobre violencia de género en la jurisprudencia de la Corte Interamericana de Derechos Humanos: el caso del penal Miguel Castro Castro; un hito histórico para Latinoamérica”, en Revista CEJIL, núm. 3, 2007, págs. 30-45, en la que se analiza la primera sentencia que aplicó el Convenio de Belém do Pará.

${ }^{10}$ Lo desarrollo más detalladamente en DE LA HERRÁN RUIZ-MATEOS, S., "La intervención estatal en la erradicación de la violencia contra las mujeres como un compromiso con los Derechos Humanos: el caso 
integralmente a la violencia contra la mujer, esto es, desde todas las aristas en las que puede revelarse y en los distintos modos de violencia, ya sea desde la más tradicional de la violencia física o psíquica contra la esposa, pareja o expareja, hasta la violencia sobre los hijos, la económica o la sexual, con independencia de los vínculos familiares y afectivos previos ${ }^{11}$. El texto además obliga a los Estados a ocuparse desde un punto de vista holístico y con diligencia debida de esta modalidad de violencia, lo cual ha llevado a que se estén dando modificaciones legislativas tendentes a acoger esta nueva perspectiva. Sin ir más lejos, en España se ha aprobado el Pacto de Estado Español contra la violencia de género de 2017 y otras recientes reformas, como la que en estos momentos se lleva a cabo en el ámbito de la libertad sexual con el Proyecto de Ley Orgánica de Garantía de la Libertad Sexual, que incorporan expresas referencias al espíritu del Convenio de Estambul ${ }^{12}$. Como se ha apuntado, el Convenio de Estambul mandata a los Estados a actuar con diligencia debida, lo que a su vez ha permitido al TEDH refrendar y reforzar sus decisiones cuando se trata de medir la responsabilidad estatal en supuestos de vulneración de derechos humanos por situaciones de violencia de género.

La Unión Europea, por su parte, no consagró expresamente el derecho a la igualdad y la prohibición de discriminación hasta la aprobación del Tratado de Lisboa ${ }^{13}$ (2007). En la actualidad se ha avanzado con el vigente Tratado de la Unión Europea, que eleva la igualdad a uno de sus valores fundamentales, junto con la dignidad, la democracia y el respeto a los derechos humanos; y en el ámbito del Tratado de Funcionamiento de la Unión Europea se ha incorporado la obligación de incluir la perspectiva de género en todas sus acciones. Sin embargo, ha sido vacilante en lo que se refiere a la violencia de género, al poner más la atención en otros aspectos como la discriminación laboral ${ }^{14}, \mathrm{y}$ una vez explorado ese camino lo ha hecho a través de las denominadas Resoluciones del Parlamento Europeo y Recomendaciones, cuya naturaleza jurídica se caracteriza, en las primeras, por una obligatoriedad difusa al situarse en el campo de los actos atípicos, y en

de España", en Revista Electrónica de Estudios Penales y de la Seguridad, núm. Especial 7, 2021, págs. 8 y ss.

${ }^{11}$ Vid., en extenso el trabajo de GIL RUIZ, J.M. (Dir.), VV.AA., El Convenio de Estambul como marco de derecho antisubordiscriminación, Dykinson, Madrid, 2018.

${ }^{12}$ Sobre ambos trabajos pueden leerse las contribuciones de ACALE SÁNCHEZ, M., "Aspectos penales del Pacto de Estado español contra la violencia de género", en Rivista di Diritto penale contemporaneo, núm. 1, 2018; y «La reforma de los delitos contra la libertad sexual de mujeres adultas: una cuestión de género», en MONGE FERNÁNDEZ, A. (Dir.), PARRILLA VERGARA, J., (Coord.), Mujeres y Derecho: ¿necesidad de una reforma desde una perspectiva de género?, Bosch editor, Barcelona, 2020, págs. 215 y ss.

${ }^{13}$ En opinión de ACALE SÁNCHEZ este reconocimiento supone un cambio de paradigma en los objetivos de la Unión, que pasa de ser entendida como un espacio para los comerciantes para ser considerada un espacio para las personas (Violencia sexual de género contra las mujeres adultas. Especial referencia a los delitos de agresión y abuso sexuales, Reus, Madrid, 2019, págs. 89 y ss.). Además, otro hecho muy importante ha sido que con este Tratado la Carta de Derechos Fundamentales de la Unión ha adquirido el mismo valor jurídico de los Tratados, lo que habilita el TJUE a pronunciarse sobre su contenido y el respeto que hacía ellos tienen los Estados en sus acciones (MANGAS MARTÍN, A., LIÑAN NOGUERAS, D.J., Instituciones y Derecho de la Unión Europea, Tecnos, Madrid, 2015, pág. 446).

${ }^{14}$ Así se relata en LOUSADA AROCHENA, J.F., "Encuentros y desencuentros entre el TEDH y el TJUE en materia de igualdad de género", en Femeris, vol. 4, núm. 2, 2019, págs. 39-49. 
las segundas, por su carácter no vinculante, lo que ha ocasionado que sean instrumentos jurídicos que escapan al control jurisdiccional del Tribunal de Justicia de la Unión Europea $^{15}$. Hasta la fecha, la contribución más relevante en la materia ha sido la aprobación de la Directiva 2012/99/UE del Parlamento Europeo y del Consejo de 25 de octubre de 2012, que establece unas normas mínimas sobre derechos, apoyo y protección a las víctimas de delitos ${ }^{16}$. Por otra parte, fue muy importante el acontecimiento del pasado 11 de mayo de 2017, cuando el Consejo firmó el Convenio de Estambul. Queda pendiente su ratificación, momento en el que adquirirá vigencia para todos los Estados integrantes de esta organización internacional, inclusive las obligaciones de diligencia debida en violencia contra la mujer ${ }^{17}$.

Finalmente, España también ha construido su propio armazón normativo para combatir esta clase de criminalidad. Se parte de la Constitución Española, cuyo art. 14 consagra el derecho a la igualdad y veda cualquier tipo de discriminación, y su importancia se mide en la forma en que ha sustentado posteriormente toda la cimentación y articulación normativa de programas de discriminación positiva ${ }^{18}$, como bien se encargó de reseñar el Tribunal Constitucional en la STC 59/2008, de 14 de mayo. Sin embargo, el gran avance llegó con la Ley Orgánica 1/2004, de 28 de diciembre, de Medidas de Protección Integral contra la Violencia de Género (en adelante, LOMPIVG). Pese a que es indiscutible que esta ley supuso una aportación muy positiva, se le ha objetado que no fue tan ambiciosa como se esperaba en un principio, pero en la actualidad se han puesto en marcha las enmiendas necesarias para la subsanación de esos defectos en el ámbito del Pacto de Estado Español contra la Violencia de Género de 2017. Por otro lado, España cuenta con la Ley Orgánica 3/2007, de 22 de marzo, para la igualdad efectiva de mujeres y hombres, que, además de desarrollar un conjunto de políticas públicas de integración de la mujer en aquellos sectores de los que ha sido excluida históricamente, presta atención a otras violencias silenciadas por la LOMPIVG, como el acoso sexual y sexista. Asimismo, y con especial incidencia en violencia de género, la Ley 4/2015, de 27 de abril, del Estatuto

\footnotetext{
${ }^{15}$ Cfr., MANGAS MARTÍN, A., LIÑAN NOGUERAS, D.J. Instituciones y Derecho de la Unión Europea, op. cit., págs. 384-385.

${ }^{16}$ En este sentido, VILLACAMPA ESTIARTE, C., "La protección de las víctimas en el proceso penal: consideraciones generales e instrumentos de protección", en TAMARIT SUMALLA, J.M. (Coord.), El estatuto de las víctimas de delitos: comentario a la Ley 4/2015, Tirant lo Blanch, Valencia, 2015, págs. 157 y ss.; ACALE SÁNCHEZ, M, Violencia sexual de género contras las mujeres adultas. Especial referencia a los delitos de agresión y abuso sexuales, op. cit., págs. 91-95.

${ }^{17}$ Esto se produce como consecuencia del principio de eficacia directa -ya asentado desde la histórica STJUE Van Gend en Loos de 5 de febrero de 1963-, por lo que incluso en aquellos Estados en los que no se haya ratificado el Convenio de Estambul será plenamente aplicable y exigible. De no haber quedado paralizado el proceso de integración de Turquía en la Unión Europea tras las reticencias que ha mostrado esta por las violaciones de derechos humanos de ese Estado este hubiese sido un buen ejemplo de la fuerza vinculatoria de los principios de eficacia directa después de que Turquía anunciara el pasado marzo de 2021 que abandonaba su adhesión al Convenio de Estambul.
}

${ }^{18}$ Sobre el particular, LAURENZO COPELLO, P., "La discriminación en el Código penal de 1995", en Revista de Estudios Penales y Criminológicos, XIX, 1996, págs. 233 y ss.; la misma autora, "La discriminación por razón de sexo en la legislación penal", en Revista de Jueces para la Democracia, núm. 34, 1999, pág. 19. 
de la Víctima, prevé medidas especiales para las víctimas especialmente vulnerables, en cuyo grupo están comprendidas las mujeres. Sobre esto último, adquiere especial significación el derecho a la protección, concretado en el art. 544 ter de la Ley de Enjuiciamiento Criminal, que ha sido considerado como parte integrante del derecho a la tutela judicial efectiva de las víctimas de violencia contra la mujer (STC 87/2020, de 20 de julio) y que, a los efectos de este trabajo, está generando responsabilidad estatal por una mala puesta en funcionamiento por parte de los agentes estatales encargados de su concesión. La controversia afortunadamente se ha apaciguado después de que en el año 2018 se haya descargado de importancia a la orden de concesión, que hasta entonces era el único título habilitante para el acceso al estatuto de la víctima por violencia de género ${ }^{19}$.

De todo lo visto hasta ahora, se concluye que uno de los principales hitos ha sido el de consensuar que hablar de violencia de género es hablar de vulneración de derechos humanos y, como tal, no debe existir discusión alguna acerca de su protección: es un derecho de mínimos. Desde esta premisa, no puede soslayarse la "diligencia debida" como estándar de protección internacional de los derechos humanos ${ }^{20}$. Pues, en efecto, el concepto de diligencia debida ha coexistido a la expansión y el reforzamiento de las medidas destinadas a proteger derechos humanos y a prevenir su infracción. Es un concepto que se proyecta sobre la responsabilidad de las entidades llamadas a observar la pervivencia e indemnidad de aquellos ${ }^{21}$. Los Estados quedan de este modo corresponsabilizados jurídicamente. Es importante insistir en que la actual respuesta estatal a la violación de derechos humanos se desprende de expresos mandatos jurídicos de orden internacional y, en su caso, interamericano o europeo. Y es que, en definitiva, basta hablar de derechos humanos para comprender incluida la violencia contra la mujer, pues como se ha visto la ONU, la OEA o el Consejo de Europa han acordado que la violencia de género es la manifestación más patente de violación sistémica de Derechos Humanos. Sin ir más lejos, ONU Mujeres ha cifrado que la violencia por razón de género afecta al 35\% de la población mundial femenina, cifras que se incrementan hasta el $70 \%$ en algunos países ${ }^{22}$. La especial atención a la violencia de género desde el prisma de los derechos humanos reconocidos internacionalmente ha venido propiciada cuantitativa y cualitativamente por la crudeza de la realidad del fenómeno, lo que ha llevado a que las normas exijan deberes a los Estados en el correcto tratamiento de las situaciones de violencia de género y una lucha constante en la búsqueda de su erradicación.

\footnotetext{
${ }^{19}$ Cfr., Real Decreto-Ley 9/2018, de 3 de agosto, de medidas urgentes para el desarrollo del Pacto de Estado contra la violencia de género.

${ }^{20}$ LOZANO CONTRETAS, J.F., La noción de debida diligencia en Derecho internacional público, Atelier, Barcelona, 2007, págs. 231 y ss.

${ }^{21}$ Véanse, por ejemplo, los Principios Rectores de la ONU sobre Empresas y los Derechos Humanos que establece un elenco de medidas organizativas para la protección, prevención y represión de cualquier atentado contra los DDHH. Disponible en: https://www.escrnet.org/sites/default/files/human_rights_due_diligence_briefing_paper_first_draft_sept_2015_-_span.pdf

${ }^{22}$ Datos de ONU Mujeres. Disponible en: https://www.unwomen.org/es/what-we-do/ending-violenceagainst-women/facts-and-figures\#notes
} 


\section{LA DILIGENCIA DEBIDA REFORZADA COMO PARÁMETRO DE MEDICIÓN DE LA RESPUESTA INSTITUCIONAL A LA VIOLENCIA DE GÉNERO}

\subsection{El estándar de diligencia debida en el marco de los derechos humanos}

No resulta sencillo ofrecer un concepto claro de "diligencia debida", pero ello no impide afirmar desde el inicio que se está ante el parámetro de medición adecuado en la evaluación de la responsabilidad estatal y de las administraciones públicas por una atención negligente a situaciones de violencia de género.

Este ha sido el criterio que ha permitido que hoy en día los Estados estén sometidos a responsabilidad por violaciones directas, indirectas u omisivas de derechos humanos $\mathrm{y}$, de modo expreso, por aquellos atentados que afectan a las mujeres en un contexto de discriminación y subordinación histórica. Acudiendo a los principios y a las reglas proporcionadas por este instrumento de valoración, los organismos jurisdiccionales -CIDH y TEDH principalmente- han comenzado a dictaminar resoluciones condenatorias por falta de diligencia debida, ya sea por la ausencia de medidas de prevención, o por la ausencia o deficiencia en la investigación y reparación después de la perpetración de estas violaciones.

La llegada de la diligencia debida como un factor de medición de la respuesta estatal a la violencia de género no puede comprenderse sin resaltar, de nuevo, la afirmación de que este no es sino un supuesto de violación de derechos humanos. Este es, y no otro, su antecedente. En efecto, este ha sido el criterio seguido históricamente para atribuir responsabilidad estatal debido a la infracción de obligaciones internacionales de protección, prevención y represión de actos lesivos para bienes e intereses jurídicos protegidos por el ordenamiento jurídico internacional. La diligencia debida, en este caso, opera en un doble sentido: a) por los denominados "hechos de Estado", es decir, por actos emanados del poder público y agentes estatales ${ }^{23}$; b) por actos de agentes no estatales en los que el Estado no hubiera impulsado medidas de prevención, investigación o resarcimiento con ocasión del hecho lesivo o dañoso de un tercero ${ }^{24}$.

En este sentido, ha tenido la oportunidad de pronunciarse tanto la CIDH como el TEDH. El primero de ellos fue pionero en determinar bajo el parámetro de la diligencia debida la responsabilidad internacional de un Estado por actos de agentes no estatales en el asunto Velásquez Rodríguez c. Honduras en 1988 con causa en la falta de diligencia en el cumplimiento de sus obligaciones para la prevención de violaciones de derechos

\footnotetext{
${ }^{23}$ LOZANO CONTRERAS, J.F. La noción de debida diligencia en Derecho internacional público, op. cit., págs. 70-99

${ }^{24}$ GÓMEZ RESTREPO, A., HERRERA TOVAR, D.F., "La debida diligencia judicial y la protección de los derechos humanos de las mujeres en contextos de violencia”, en Revista Iustitua, núm. 16, 2018, pág. 89.
} 
humanos $^{25}$, y desde entonces lo ha reafirmado constantemente ${ }^{26}$ con un desarrollo jurisprudencial que asocia los deberes de investigación y sanción de violaciones de derechos humanos a la protección de derechos individuales como la vida ${ }^{27}$, la integridad física o el derecho a la tutela judicial efectiva de las víctimas ${ }^{28}$. Por su parte, el TEDH también se ha pronunciado en la misma, es decir, ha asentado su jurisprudencia disociando las obligaciones estatales en un deber de abstención, que obliga a las autoridades y órganos estatales a no vulnerar los derechos reconocidos en el CEDH, y un deber de protección que obliga a prevenir, perseguir y reprimir este tipo de $\operatorname{conductas}^{29}$.

Otro aspecto de calado que debe mencionarse desde el punto de vista propuesto en este trabajo, es lo que se ha denominado "fertilización cruzada jurisprudencial"30 y que consiste en un método por el que ambos órganos jurisdiccionales apoyan y retroalimentan su doctrina en los pronunciamientos del otro. Esto propicia que pueda hablarse de la construcción de una teoría de los derechos humanos planetaria, cuya validez es extensible a los hechos sucedidos en Centroamérica, en el continente europeo o en el asiático. No obstante, pese a que la CIDH también ha refrendado sus decisiones acudiendo a las del TEDH ${ }^{31}$, se coincide con LOZANO CONTRENAS ${ }^{32}$ cuando señala que la CIDH ha demostrado un mejor manejo de las fuentes que sostienen los deberes de prevención y represión impuestos por la diligencia debida, y que también se ha reflejado en el ámbito de la violencia de género, no solo por la existencia de una legislación mucho más detallada en el desarrollo del contenido de la debida diligencia, sino por una mejor

25 DE LEÓN, G., KRSTICEVIC, V., OBANDO, L., Debida diligencia en la Investigación de Graves Violaciones a Derechos Humanos, CEJIL, Argentina, 2010, pág. 2. Este caso fue sometido a la CIDH por la Comisión Interamericana de Derechos Humanos en abril de 1896 tras la interposición de una denuncia contra el Estado de Honduras por la desaparición y asesinato de Ángel Manfredo Velásquez Rodríguez a manos de miembros de la Dirección Nacional de Investigación e Inteligencia de las fuerzas armadas hondureñas.

${ }^{26}$ Vid., SCIDH Juan Humberto Sánchez c. Honduras; o Bulacio c. Argentina de 18 de septiembre de 2003.

${ }^{27}$ SCIDH Ximenes Lopez c. Brasil, de 4 de julio de 2006; Comunidad Indígena Swahytamaxa c. Paraguay, de 29 de marzo de 2006; Caso Masacre Pueblo Bello c. Colombia, de 31 de enero de 2006.

${ }^{28}$ SCIDH Caso de la Masacre de la Rochela c. Colombia, de 11 de mayo de 2007.

${ }^{29}$ Así se hizo por primera vez en el asunto Osman c. Reino Unido, sentencia de 28 de octubre de 1988. Aunque la sentencia resultó absolutoria para el Estado, el TEDH admitió que las obligaciones de prevención y presión estaban implícitamente contempladas en el Convenio y que su incumplimiento estaba sometido a la posible declaración de responsabilidad del Estado. Posteriormente, en el asunto Mahmut Haya c. Turquía de 28 de marzo de 2000, el TEDH, en aplicación de lo que ya venía indicando, condenó al Estado de Turquía por no hacer lo que razonablemente se esperaba para prevenir el secuestro, tortura y asesinato de Hasan Kaya y no investigar adecuadamente los hechos. En similar sentido, se pronunció en el asunto Akkoc c. Turquía, de 10 de octubre de 2000. Para más detalle, léase LOZANO CONTRERAS, José Fernando, La noción de debida diligencia en Derecho internacional público, op. cit., págs. 242-250.

30 Ampliamente, MACULAN, E., "La fertilización cruzada jurisprudencial y los modelos de responsabilidad. Acordes y desacuerdos en la jurisprudencia latinoamericana", en GIL GIL, A., (Dir.), MACULAN, E., (Coord.), Intervención delictiva y derecho penal internacional: reglas de atribución de la responsabilidad en crimenes internacional, Dykinson, Madrid, 2013, págs. 69-144

${ }^{31}$ Entre otros, en el asunto Masacre de Pueblo Bello c. Colombia ya indicado.

${ }^{32}$ Cfr., LOZANO CONTRERAS, J.F., La noción de debida diligencia en Derecho internacional público, op. cit., págs. 258 . 
integración de la perspectiva de género. Mientras que el TEDH afrontó la violencia contra la mujer de un modo individualizado, sin tener en consideración los factores socioculturales que propician y sistematizan esta clase de violencia, hasta la STEDH Opuz c. Turquía, de 9 de junio de 2009, la CIDH ya avanzó en esta línea en su sentencia de 25 de noviembre de 2006 en el caso Miguel Castro Castro c. Perí ${ }^{33}$, aunque ya con anterioridad, en el año 2001, había emitido un informe relativo al caso María da Penha Maia Fernandes en el que reconocía que las mujeres sufrían una especial discriminación por parte de los sistemas institucionales y judiciales precisamente por no ser capaces de adecuar su actuación a la especificidad del fenómeno ${ }^{34}$.

La utilidad de este criterio en la valoración del grado de responsabilidad de los Estados en supuestos de violación de derechos humanos invita a extrapolarlo a todos aquellos asuntos en que los hechos respondan a situaciones de violencia contra la mujer. Esta conclusión se alcanza, como no puede ser de otro modo, después de que todos los organismos internacionales - ONU, OIE, Consejo Europeo, Unión Europea- y su acervo normativo hayan entendido que la violencia contra la mujer es uno de los mayores atentados contra los derechos humanos en la actualidad. La conclusión de que esta modalidad de violencia no es más que una tipología de todas las que se subsumen dentro de la amplia esfera de los derechos humanos ha obligado a que sea este y no otro el criterio de valoración utilizado para medir la responsabilidad en la que los Estados pueden incurrir en los casos de atención deficiente o negligente en violencia de género ${ }^{35}$, y así se aplica por parte de la CEDAW, el CIDH, el TEDH y los organismos jurisdiccionales nacionales, como los españoles. A mayor abundamiento, no solo bastará con la diligencia debida en el sentido más tradicional, sino que será necesaria la exigencia de un deber reforzado de diligencia debida para el Estado con la incorporación de la perspectiva de género al enjuiciamiento.

\subsection{La diligencia debida en la Corte Interamericana de Derechos Humanos}

En efecto, como se decía con anterioridad, la contribución de la CIDH a la construcción del estándar de diligencia debida en derechos humanos es muy sustanciosa. Y así lo ha mantenido cuando se ha tratado de proteger los derechos humanos de las mujeres en contextos de violencia. Se ha visto ya cómo este órgano fue pionero en el uso de la debida

\footnotetext{
${ }^{33}$ Sin embargo, tampoco se ha sustraído a las críticas que objetan a la Corte que haya tardado más de 20 años desde la aprobación del Convenio de Belém do Pará en incorporar al enjuiciamiento la perspectiva de género que ahí se contiene. En este sentido, es crítico, VOLGELFANGER, A.D., «El deber de prevención en casos de violencia de género: desde "Campo Algodonero" hasta "Veliz Franco"», en Eunomía, Revista en Cultura de la Legalidad, núm. 9, octubre 2015 - marzo 2016, pág. 52.

${ }^{34}$ CIDH, Informe Núm. 54/01, caso 12.051, María da Penha Maia Fernandes vs. Brasil, de 16 de abril de 2001. Posteriormente lo ha venido manteniendo, en casos como los sustanciados en las sentencias Fernández Ortega y otros c. México, de 30 de agosto de 2010 o Rosendo Cantú y otra c. México, de 31 de agosto de 2010.

35 En el mismo sentido, CASTRO-RIAL GARRONE, F., "Los derechos de las personas en situación vulnerable: mujeres, niños, inmigrantes", en BLANC ALTEMIR, A. (Dir.)., VV.AA., La protección internacional de los derechos humanos a los cincuenta años de la declaración universal, Tecnos, Madrid, 2001, pág. 313.
} 
diligencia como parámetro de medición de la responsabilidad estatal por la falta de prevención en la violación de derechos humanos -SCIDH, Velásquez Rodríguez c. Honduras, de 29 de julio de 1988-, así como en la incorporación de la perspectiva de género al estudio, análisis y enjuiciamiento de casos de violencia sistémica contra la mujer-SCIDH Miguel Castro Castro c. Perú, de 25 de noviembre de 2006. No obstante, en lo que se refiere a la atribución de responsabilidad del Estado por actos de terceros y deber de prevención no fue hasta el año 2009, en el caso Campo Algodonero, que no combinó ambos aspectos en la valoración de un mismo asunto ${ }^{36}$.

Con la sentencia González y otras c. México ('Caso Algadonero'), de 16 de noviembre de 2009, la CIDH determinó por primera vez la responsabilidad de un Estado, México, por la infracción del deber de prevención e investigación que exigía la diligencia debida en un supuesto de violencia sexual de género. Las instituciones mexicanas, después de recibir la denuncia de la desaparición de tres jóvenes, no llevaron a cabo actuación alguna bajo la creencia de que se habían marchado voluntariamente con un hombre. Lo más llamativo de esta sentencia es que incorpora en el enjuiciamiento la perspectiva de género al reprochar que la decisión de las autoridades formaba parte de los estereotipos sociales del género e infiere que en estos casos se está en presencia de una obligación reforzada de diligencia debida precisamente por las exigencias que desprende el Convenio de Belém do Pará ${ }^{37}$. Es decir, y ahí se halla el objeto central de la discusión, es la perspectiva de género la que eleva las exigencias formales y materiales de la diligencia debida tradicional que se aplicaba en materia de derechos humanos, pues, como dice la sentencia, "en casos de violencia contra la mujer, los Estados tienen, además de las obligaciones genéricas contenidas en la Convención Americana, una obligación reforzada a partir de la Convención Belém do Pará” (párr. 258).

Esta sentencia delimita el contenido de la diligencia debida reforzada en violencia de género al considerar que el Estado tiene una obligación ex ante que debe desenvolverse en el campo de la acción legislativa y una ex post que se materializa en las labores de investigación, persecución y reparación que se derive de los hechos que, en su caso, acontezcan. En este sentido, continúa matizando la $\mathrm{CIDH}$, la responsabilidad del Estado por actos de agentes no estatales no es ilimitado, sino que se ha de definir en función del conocimiento del riesgo real o inmediato para las víctimas ${ }^{38}$, pues es del único modo en

\footnotetext{
${ }^{36}$ Sobre esta confluencia CALDERÓN CAMBOA, J., RECINOS, J.D., "La perspectiva de género en casos de violencia sexual en conflicto armado: aportes de las Sentencias de la Corte IDH en los casos Las Masacres de las dos Erres Vs. Guatemala y Espinoza Gonzáles Vs. Perú", en PARRA VERA et al. (Eds.), La lucha por los Derechos Humanos hoy. Estudios en homenaje a Cecilia Medina Quiroga, Tirant lo Blanch, Valencia, 2017, págs. 405-434.

${ }^{37} \mathrm{Vid}$, el análisis sobre la dimensión histórica y social de la violencia contra la mujer en el marco del deber de prevención que se hace en MARTÍNEZ VARGAS, J.R., VEGA BARBOSA, G., «La obligación estatal de prevención a la luz del corpus iuris internacional de protección de la mujer contra la violencia de género», en Revista Ius et Praxis, núm. 2, 2019, págs. 344-348.

${ }^{38}$ SCIDH, González y otras c. México, de 16 de noviembre de 2009 (Párr. 282); En opinión de MARTÍNEZ VARGAS y VEGA BARBOSA la denuncia surge como el factor que determina la concreción de los deberes de prevención del Estado, de tal manera que permite exigirle una actuación particular de protección
} 
que se concretizan los deberes de diligencia debida que el Estado está llamado a integrar. Desde este momento, la responsabilidad del Estado puede apreciarse, en primer lugar, por una ausencia de política de igualdad de género, en los casos de falta de adopción de un marco jurídico de protección adecuado, con medidas concretas de prevención que aglutinen el reconocimiento del género como un factor de victimización con connotaciones propias; y en segundo lugar, por la falta de respuesta institucional por parte de las autoridades estatales en la protección de las víctimas, investigación de los hechos, así como en el acceso a la justicia o la reparación adecuada. En relación con este segundo ámbito de responsabilidad, la SCIDH Veliz Franco y otros c. Guatemala, de 19 de mayo de 2014, analiza la posible vinculación causal que, de algún modo, puede darse entre el incumplimiento de las autoridades estatales en el establecimiento de medidas de prevención e investigación efectiva de una denuncia por desaparición y el posterior resultado de muerte. La Corte llega a la conclusión de que el Estado de Guatemala fue responsable en la infracción de los deberes de diligencia debida al no actuar cuando recibió la denuncia de la desaparición, y reprocha a las autoridades guatemaltecas que de haber llevado a cabo una investigación eficiente se hubiese contribuido a disminuir el riesgo de muerte. De hecho, apostilla, que la ausencia de investigación vedaba cualquier posibilidad de saber si la víctima estaba muerta en el momento de la denuncia. Caso parecido sucede en el caso Velázquez Paiz y otros c. Guatemala, sentencia de 19 de noviembre de 2015, en el que la CIDH vincula la falta de implementación de las medidas necesarias requeridas por el art. 2 de la Convención Americana de Derechos Humanos y el art. 7 del Convenio de Belém do Pará a la imposibilidad de prevenir e investigar adecuadamente unos hechos que se insertan en un contexto de violencia contra la mujer.

En todos estos casos, y en sucesivos, la CIDH ha "sancionado" a los Estados a la formación y capacitación material a sus funcionarios en la materia, así como a crear o adecuar sus protocolos a los estándares internacionales en esta clase de violencia. Especialmente significativa ha sido la condena a los Estados consistente en el deber de diseñar programas educativos dirigidos a la erradicación de los estereotipos y la violencia de género ${ }^{39}$.

\subsection{La diligencia debida en el Tribunal Europeo de Derechos Humanos}

La aportación europea, en su mayoría, ha venido de la mano del TEDH. Sin embargo, tradicionalmente se le ha objetado ser en su jurisprudencia un órgano ciertamente reticente a la hora de impulsar los derechos a la igualdad y a la no discriminación por

como medida de prevención ("La obligación estatal de prevención a la luz del corpus iuris internacional de protección de la mujer contra la violencia de género", op. cit., pág. 352).

${ }^{39}$ CALDERÓN CAMBOA, J., RECINOS, J.D., "La perspectiva de género en casos de violencia sexual en conflicto armado: aportes de las Sentencias de la Corte IDH en los casos Las Masacres de las dos Erres Vs. Guatemala y Espinoza Gonzáles Vs. Perú”, op. cit., págs. 405-434. 
razón de género. Sin embargo, se coincide con CARMONA CUENCA ${ }^{40}$ cuando señala que en los últimos años se ha asistido a una evolución encomiable en favor del análisis de la actuación de los Estados como entes generadores de violencia o discriminación directa e indirecta, así como de la incorporación de la diligencia debida en la implementación de medidas de acción positiva para combatir la violencia de género. En definitiva, se valora positivamente su creciente compromiso y preocupación con el derecho humano a la igualdad de género y la no discriminación.

Las vacilaciones jurisprudenciales del TEDH en violencia de género y doméstica traen causa en la ausencia de perspectiva de género hasta la sentencia Opuz c. Turquía, de 9 de junio de $2009^{41}$. En efecto, hasta esta sentencia el TEDH había afrontado la violencia contra la mujer de un modo individualizado y no como un problema social de corte internacional, sin tener en consideración los factores socioculturales que propician y perpetúan esta clase de violencia ${ }^{42}$. Hasta ese momento los asuntos sometidos a su conocimiento relativos a violencia doméstica o de género habían sido vistos desde el estricto desvalor del resultado, esto es, desde el contenido del derecho a la vida (art. 2 $\mathrm{CEDH}$ ) o la integridad física y moral (art. $3 \mathrm{CEDH}$ ), sin relacionar estos dos con el derecho antidiscriminatorio (art. $14 \mathrm{CEDH})^{43}$.

Sin embargo, con el logro de incorporar el art. 14 del CEDH a la casuística del género se consigue enjuiciar la responsabilidad de los Estados de un modo bifronte: en primer lugar, desde la demanda histórica del estricto respeto a los derechos y libertades consagradas en el texto, esto es, a no generar discriminaciones directas o indirectas ya sea a través de su normativa o de sus operadores institucionales y estatales; y, en segundo lugar, y he aquí la novedad, desde las exigencias a la acción positiva a la que están obligados. De este modo, los Estados no solo asumen un deber de abstención ante toda posible clase de injerencia, sino que están obligados a poner en funcionamiento sistemas efectivos de protección a las víctimas y de prevención y persecución del delito, lo que requiere un esfuerzo reforzado precisamente por la representación de la mujer como parte de un colectivo históricamente discriminado ${ }^{44}$. A colación de esto último, y aunque el art. 4 de

\footnotetext{
${ }^{40}$ Vid., CARMONA CUENCA, E., "La igualdad de género en el Tribunal Europeo de Derechos Humanos: un reconocimiento tardío con relación al Tribunal de Justicia de la Unión Europea", en Revista Española de Derecho Constitucional, núm. 104, 2015, pág. 298.

${ }^{41}$ Esta sentencia tiene el mérito de entroncar la violencia de género bajo el paraguas de los derechos humanos, así como insiste en las obligaciones de los Estados de diseñar medidas de protección para las víctimas. Se analiza pormenorizadamente en LÓPEZ-JAICOSTE DÍAZ, E., "Violencia doméstica y malos tratos en el Tribunal Europeo de Derechos Humanos", en Anuario Español de Derecho Internacional, vol. XXV, 2009, págs. 383-411.

${ }^{42}$ Cfr., CARMONA CUENCA, E., "Los principales hitos jurisprudenciales del Tribunal Europeo de Derechos Humanos en materia de igualdad de género", en Revista de Teoría y Realidad Constitucional, núm. 42, 2018, págs. 324-328.

${ }^{43}$ En este sentido, SSTEDH Kontrová c. Eslovaquia, de 31 de mayo de 2007; Branko Tomasic c. Croacia, de 15 de enero de 2009.

${ }^{44}$ En el mismo sentido, LÓPEZ-JAICOSTE DÍAZ, E., "Violencia doméstica y malos tratos en el Tribunal Europeo de Derechos", op. cit., págs. 384-389.
} 
la Declaración sobre la eliminación de la violencia contra la mujer de 1993 ya mencionaba en su apartado c) que con el fin de eliminar la violencia contra la mujer debían "proceder con la diligencia debida a fin de prevenir, investigar y, conforme a la legislación, nacional, castigar todo acto de violencia contra la mujer [...]", hay que señalar la gran contribución del TEDH, iniciada en la sentencia Opuz c. Turquía, de 9 de junio de 2009, en el desarrollo y estandarización de dicho deber, y que posteriormente se ha reflejado en la regulación del Convenio de Estambul.

El deber de diligencia que recae sobre los Estados busca eliminar cualquier resquicio de pasividad, omisión o negligencia en las labores de prevención y protección (SSTEDH Opuz c. Turquía, de 9 de junio de 2009; M.G. c. Turquía, de 22 de marzo de 2016), incluidas las labores de investigación judicial y policial (STEDH Talpis c. Italia de 2 de marzo de 2017). Deber que, como reseña la Sentencia del TEDH en el asunto Talpis $c$. Italia, es exigible más allá de toda duda al haber quedado normativizado en el art. 5 del Convenio de Estambul bajo el título "Obligaciones del Estado y diligencia debida" 45 . Esta senda argumentativa ha servido al TEDH para condenar a Rusia (STEDH, Volodina c. Russia, de 9 de julio de 2019) tanto por una inadecuada protección a una víctima de violencia doméstica, como por la ausencia de un concepto que defina la violencia doméstica y que reconozca el carácter sistémico de esta clase violencia sufrida, con connotaciones propias, por las mujeres. Hay que resaltar que hasta este momento no se había emitido una sentencia que con tanta rotundidad considere una conculcación de los derechos humanos la ausencia en una legislación nacional de un concepto específico y adecuado de violencia de género.

Finalmente, es muy interesante la reciente sentencia de la Gran Sala del TEDH (STEDH Kurt c. Austria, de 15 de junio de 2021), que en un caso de violencia vicaria - asesinatoha entrado a analizar el alcance de las obligaciones estatales en la evaluación integral del riesgo. El asunto del que trae causa el pronunciamiento del TEDH es la desestimación de la demanda por responsabilidad estatal en una inadecuada valoración del riesgo y la insuficiencia de la orden de protección para evitar el resultado muerte finalmente acaecido. La demandante, madre del hijo asesinado, alegaba que la justicia tuvo más que suficientes indicios para llegar a la conclusión de que el resultado de muerte era previsible y que justificaba la disposición de medidas cautelares como la prisión preventiva para evitar el asesinato. Se sostenía en la demanda ante el TEDH la vulneración por parte de las autoridades nacionales del art. 2 del CEDH que mandataba positivamente a proteger la vida de sus hijos y la suya propia. Pese a que en el expediente obraban amenazas textuales del tipo "mataré a nuestros hijos frente a $t i$ ” y la acreditación clínica de agresiones físicas a los menores, así como físicas y sexuales a la demandante, se consideró

\footnotetext{
${ }^{45}$ Artículo 5 - Obligaciones del Estado y diligencia debida: "1. Las Partes se abstendrán de cometer cualquier acto de violencia contra las mujeres y se asegurarán de que las autoridades, los funcionarios, los agentes y las instituciones estatales, así como los demás actores que actúan en nombre del Estado se comporten de acuerdo con esta legislación. 2. Las partes tomarán las medidas legislativas y otras necesarias para actuar con la diligencia debida para prevenir, investigar, castigar y conceder una indemnización por los actos de violencia incluidos en el ámbito de la aplicación del presente Convenio cometidos por actores no estatales".
} 
suficiente el dictado de una orden de alejamiento. Esto no impidió que el padre fuese al encuentro del hijo al colegio y lo ejecutara con un disparo en la cabeza. Después de haber cumplido su amenaza, el padre se suicidó. Esta sentencia, dictada tan solo días después de que España haya quedado conmocionada por el asesinato de dos niños en Tenerife a manos de su padre, pone de manifiesto la necesidad de atender integralmente al fenómeno de la violencia contra la mujer, y que, por supuesto, se extiende a la violencia ejercida contra los hijos con la finalidad de hacer daño a la madre, como bien menciona la sentencia al examinar el contenido del Convenio de Estambul (párr. 75 y ss.) y el informe del GREVIO (párr. 87 y ss.). En la sentencia se pone claramente de manifiesto que las autoridades austriacas no observaron en el padre una personalidad capaz de llevar a cabo hechos tan graves como el asesinato del menor. El TEDH, aunque considera que en el caso no hubo retrasos o inactividad de las autoridades y que se cumplieron formalmente las obligaciones estatales con la concesión de la orden de alejamiento, reprocha al estado la falta de diligencia en la evaluación del riesgo y, en concreto, que no se hubiese concedido credibilidad a las amenazas de muerte cuando era más que perceptible la existencia de un riesgo real e inminente para la vida del menor (párr. 203 - 206). No obstante, entiende el voto mayoritario que las autoridades austriacas han cumplido sustantivamente las obligaciones positivas que desprende el art. 2 CEDH y que, por tanto, no puede declararse su violación. El voto particular, por su parte, rechaza la desestimación y aboga por declarar la falta de diligencia debida porque las medidas adoptadas no fueron adecuadas -como la ausencia de medidas en el colegio de los niños- cuando existían razones objetivas más que suficientes para la previsibilidad del resultado.

\subsection{Recepción española}

En los últimos tiempos se observa una tendencia favorable en el ámbito de la determinación de la responsabilidad del Estado español por actuaciones negligentes de sus agentes institucionales, policiales o judiciales en situaciones de violencia contra la mujer, para lo que se trae a colación todo el constructo teórico internacional de los derechos humanos del género. Esta evolución positiva no solo se percibe en la esfera judicial, sino que algunas de las reformas que en la actualidad se discuten inciden en mejorar estos aspectos, muchos de los cuales hasta ahora mostraban importantes deficiencias en su configuración, como fue advertido, entre otros organismos, por el Comité de la $\mathrm{CEDAW}^{46}$, que reprochó a España su regulación del concepto de violencia de género, al circunscribirlo al ámbito de la pareja y la familia, dejando fuera otras manifestaciones de esa misma clase de violencia, pero que se reproducen por autores desconocidos o con los que se mantienen vínculos distintos a los de parentesco o afectividad. Esta crítica, en puridad, conecta con las más tradicionales ${ }^{47}$ a la LOMPIVG, lo que pone de relieve que hasta este momento el legislador no se había esforzado en

\footnotetext{
${ }^{46}$ Comité para la Eliminación de la Discriminación contra la Mujer, Observaciones finales sobre los informes periódicos séptimo y octavo combinados de España, CEDAW/C/ESP/CO/7-8 de 29 de julio de 2017, párr. 20,

${ }^{47}$ En este sentido, MAQUEDA ABREU, M.L., "La violencia de género. Entre el concepto jurídico y la realidad social", en Revista Electrónica de Ciencia Penal y Criminología, 08-02, 2006, págs. 4 y ss.
} 
corregirlos. No obstante, ya se dijo que estos defectos han comenzado a recibir respuesta por el Pacto de Estado Español contra la violencia de género firmado en 2017, cuyas propuestas 84,85 y $86^{48}$ preconizan una posible ampliación del concepto de violencia contra las mujeres en sintonía con el contenido del Convenio de Estambul y el derecho internacional humanitario. Empero se ha echado en falta la incorporación, precisamente, de medidas encaminadas a reforzar la diligencia debida en violencia de género. En esta línea, la representante de Amnistía Internacional, en su comparecencia ante la Subcomisión del Pacto de Estado el 9 de mayo de 2019, advirtió de la trascendencia de estas omisiones normativas, así como de la ausencia de referencias legales en el ámbito de la reparación.

Con mayor optimismo se asiste a la tramitación del Proyecto de Ley Orgánica de Garantía Integral de la Libertad Sexual presentado por el Ministerio de Igualdad del Gobierno de España el pasado marzo de 2020 y que ya ha empezado su tramitación en sede parlamentaria. Este proyecto reconoce la violencia sexual como una de las múltiples caras de una violencia de género poliédrica ${ }^{49}$. Son muchos los cambios que propone el texto, pero al efecto de esta exposición resulta muy novedosa la positivación expresa de la diligencia debida frente a la violencia contra la mujer. La Exposición de Motivos apoya la justificación de esta medida precisamente en el cumplimiento de las obligaciones internacionales asumidas por España ${ }^{50}$.

El art. 2.2 del proyecto de ley orgánica establece que uno de los principios rectores de la actuación de los poderes públicos es el de "diligencia debida", para lo que "la respuesta ante las violencias sexuales se extenderá a todas las esferas de la responsabilidad institucional tales como la prevención, protección, asistencia, reparación a las víctimas y promoción de la justicia, y estará encaminada a garantizar el reconocimiento y ejercicio efectivo de los derechos". En definitiva, la necesidad de abordar el fenómeno de la violencia sexual desde la óptica que en este proyecto se procura supone en sí mismo

\footnotetext{
${ }^{48}$ Pueden verse las propuestas 84, 85 y 86 del Pacto de Estado en materia de Violencia de Género en el Boletín Oficial de las Cortes Generales de 8 de agosto de 2017, núm. 200, o en el documento refundido del Ministerio de Igualdad.

Disponible en: https://www.mineco.gob.es/stfls/mineco/ministerio/igualdad/ficheros/PactodeEstado.pdf

${ }^{49}$ En este sentido, ACALE SÁNCHEZ, M., "La visibilización de la violencia sexual como una modalidad de violencia de género", en BUSTOS RUBIO, M., ABADÍAS SELMA, A. (Dirs.), Una década de reformas penales: análisis de diez años en el Código Penal (2010-2020), Bosch, Barcelona, 2020, págs. 341-355.

50 "Esta ley orgánica pretende dar cumplimiento a las mencionadas obligaciones globales en materia de protección de los derechos humanos de las mujeres, las niñas y los niños frente a las violencias sexuales integrándose también en la política exterior española, y siguiendo el mandato del artículo 9.2 de la Constitución, remover los obstáculos para la prevención de estas violencias, así como garantizar una respuesta adecuada, integral y coordinada que proporcione atención, protección, justicia y reparación a las víctimas. Para ello, esta ley orgánica extiende y desarrolla para las violencias sexuales todos aquellos aspectos preventivos, de atención, sanción, especialización o asistencia integral que, estando vigentes para otras violencias, no contaban con medidas específicas para poder abordar de forma adecuada y transversal las violencias sexuales. Además, como novedad, se desarrolla el derecho a la reparación, como uno de los ejes centrales de la responsabilidad institucional para lograr la completa recuperación de las víctimas y las garantías de no repetición de la violencia".
} 
el cumplimiento de uno de los deberes de diligencia debida que España ha contraído en su compromiso con los derechos humanos. Así lo tiene asentado el TEDH cuando en el asunto MC c. Bulgaria, de 4 de diciembre de 2003, determinó la obligación de los Estados de tipificar e investigar adecuadamente la violencia sexual en el sentido que ahora se propone.

Se comienza así a incluir en las nuevas propuestas de reforma las exigencias internacionales más tradicionales en materia de derechos humanos; avances legislativos que coinciden con el reconocimiento que ya han incorporado paulatinamente los Tribunales españoles en su doctrina. En este sentido, resultan de interés algunos recientes pronunciamientos en los que cristaliza la recepción de la diligencia debida en nuestro país. La primera resolución que hay que mencionar es la STC 87/2020, de 20 de julio, en la que el Tribunal Constitucional (en adelante, TC) ha fallado a favor de considerar vulnerado el derecho a la tutela judicial efectiva de una víctima de violencia de género por una deficiente investigación en el curso de un proceso penal por parte del Juzgado de Violencia sobre la Mujer núm. 3 de Madrid y que desembocó en un sobreseimiento provisional prematuro. Esta sentencia es muy reveladora porque aborda un extremo procesal sobre el que hasta ahora no había jurisprudencia constitucional $-\mathrm{y}$ explica la superación del filtro de la especial trascendencia constitucional - como es la necesidad de establecer un deber de diligencia debida reforzada en la investigación judicial y en la motivación de las resoluciones judiciales que recaigan en procedimientos relacionados con violencia de género. Lo más llamativo de esta sentencia es que el TC, para fundamentar su postura, acoge todo el conglomerado jurídico de los derechos humanos del género - tanto de orden internacional como europeo- y con ese proceso de integración normativa lleva a cabo el estudio del caso. Desde su entendimiento de que la "erradicación [de la violencia de género] desencadena obligaciones positivas para los Estados, que deben tomar las medidas necesarias para proveer una protección efectiva de quienes sufran violencia basada en su género, incluyendo sanciones penales, remedios civiles y provisiones compensatorias para su protección frente a todo tipo de violencia", el TC señala que no se agota el compromiso de los Estados con la implementación y supervisión de esos instrumentos, sino que también se exige una actuación reforzadamente diligente en las tareas de investigación de los hechos, persecución de los autores y protección a las víctimas. De esta forma considera que esas exigencias son extensibles a los agentes - judiciales, policiales, asistenciales, etc. - y los organismos del Estado, cuya actuación ha de ser especialmente cuidadosa en violencia de género precisamente por tratarse de una cuestión que compromete la pervivencia de los propios derechos humanos.

Por su parte, la STS, Sala Cuarta, 1263/2018, de 17 de julio, condena al Ministerio de Justicia del Gobierno de España como administración pública patrimonialmente responsable del funcionamiento anormal de la Administración de Justicia por el incumplimiento de la resolución emitida por el Dictamen del Comité de la CEDAW ${ }^{51}$. En

\footnotetext{
${ }^{51}$ Muy detalladamente, HERNÁNDEZ LLINÁS, L., "Hijos e hijas de la mujer maltratada como víctimas de la violencia de género: el caso González Carreño contra España y la STS 1263/2018”, en DEL POZO
} 
esta sentencia el Tribunal Supremo (en adelante, TS) casa y anula la Sentencia de la Sala de lo Contencioso Administrativo de la Audiencia Nacional de 2 de noviembre de 2016 que desestimaba la pretensión de la víctima de hacer efectivo el Dictamen de la ONU que daba por acreditada la vulneración de sus derechos al no haber sido debidamente restituida después del asesinato de su hija a manos del marido de aquella y padre de esta. El hecho se perpetró como consecuencia de la falta de diligencia debida por parte de las autoridades españolas en un contexto de violencia doméstica prolongado en el tiempo. Esta sentencia tiene la virtualidad de poner a disposición de las víctimas un canal extra legem por la que hacer efectiva las resoluciones del organismo supremo de la CEDAW. La Audiencia Nacional basa su rechazo, fundamentalmente, en la ausencia de un procedimiento que posibilite la eficacia ejecutiva de los dictámenes de la CEDAW. El TS reprocha esta argumentación y hace válida toda la normativa internacional en materia de violencia contra la mujer por ser, en definitiva, una violación de derechos humanos y que, en consonancia, dice el Tribunal, "La conculcación de [los] derechos humanos, también puede constituir una lesión de [los] derechos fundamentales que debe ser examinada y en su caso reparada por los Jueces y Tribunales españoles". El TS avala lo que ya se apuntaba y es que los Tratados Internacionales en materia de derechos humanos ratificados por España y los dictámenes y resoluciones dimanantes de los órganos creados por estos tienen plena eficacia y vinculan directamente al ordenamiento jurídico interno; y no solo eso, sino que además prevalece respecto a aquellas otras normas que omitan o incumplan las obligaciones derivadas de aquellos ${ }^{52}$. Concluye el Supremo señalando que habida cuenta de la delicada materia de que se trata no puede perpetuarse una violación de derechos humanos y derechos fundamentales bajo el inane argumento de la ausencia de cauces procedimentales tendentes a lograr su eficacia -lo que ya supone una grave infracción del Estado español de la diligencia debida en violencia de género-y que, en consecuencia, la declaración de la CEDAW se instituye como título bastante para completar las exigencias de una declaración patrimonial del Estado por un funcionamiento anormal de la Administración de Justicia.

En otro orden de cosas, la Sentencia de la Sala de lo Contencioso-Administrativo de la Audiencia Nacional de 30 de septiembre de 2020 (núm. Recurso 2187/2019) condena al Ministerio del Interior como órgano administrativo patrimonialmente responsable del error cometido por la Guardia Civil en la valoración del riesgo de una víctima de violencia de género que motivó la denegación de la orden de protección y que resultó un factor decisivo en el asesinato un mes después de la interposición de la denuncia. La víctima, dominicana, madre de dos hijos pequeños y sin alternativa socioeconómica ni familiares, interpuso denuncia después de haber soportado vejaciones, amenazas de muerte, agresiones físicas y verbales y violaciones de modo continuado. Presentaba parte de facultativo de lesiones y solicitó una orden de protección, que fue denegada judicialmente

PÉREZ, M. (Dir.), BUJOSA VADELL, L. (Dir.), GONZÁlEZ MONJE, A. (Coord.), Proceso penal y víctimas especialmente vulnerables. Aspectos interdisciplinares, Aranzadi, Navarra, 2019, págs. 171 y ss.

52 GUTIÉRREZ ESPADA, C., "La aplicación en España de los dictámenes de los comités internacionales: la STS 1263/2018, un importante punto de inflexión”, Cuadernos de Derecho Transnacional, 2018, vol. $10-2$, págs. 836 y ss. 
después de que la Guardia Civil valorara el riesgo como "no apreciado”. La Audiencia Nacional, que conocía del recurso contencioso administrativo interpuesto contra la resolución que desestimaba la reclamación en vía administrativa por el funcionamiento anormal de la Guardia Civil, consideró que, en efecto, una adecuada valoración de la situación de violencia habría motivado la prestación de una orden de protección que con una alta probabilidad hubiese evitado el resultado de muerte, observando una relación de causalidad entre la actuación negligente de la Guardia Civil y la consumación del asesinato por parte de su autor. Reprocha la Audiencia Nacional a la Guardia Civil la falta de sensibilidad y, especialmente, la errada decisión después de tener a su alcance información objetiva suficiente, dice la sentencia, para que el "riesgo hubiera sido, no ya «medio», sino «alto»o «extremo»" 53. Finaliza la Audiencia Nacional asegurando que la Guardia Civil ha incumplido sus propios protocolos que reclaman tener en cuenta una serie de factores referidos a las particularidades de esta clase de violencia ${ }^{54}$, lo que "resulta tanto más grave considerando una muy preocupante realidad que, fruto de la alarma social que provoca y el firme compromiso de la sociedad para combatir la lacra de la violencia de género, reclama una particular diligencia de todos los operadores involucrados".

\section{REFLEXIONES FINALES}

En el ampliamente divulgado Feminismo para principiantes, VALERA afirma que "Transformar el concepto de derechos humanos desde una perspectiva feminista pasa por una afirmación tan obvia como utópica: los derechos de las mujeres son derechos humano" 55 . Y es que, en efecto, la incorporación del carácter "reforzado" a la tradicional diligencia debida que se exige en todo aquello que afecte a derechos humanos es el resultado de la integración de la perspectiva de género, es decir, de la aceptación de la especial vulnerabilidad de este sector de la población por razones que escapan a su control, y esa potencial exposición a la lesión de sus derechos necesita de medidas especiales y de una atención reforzada y cuidada por parte de las instituciones.

Esto ha llegado como una exigencia normativa proveniente de instancias internacionales como la CEDAW ${ }^{56}$, a la que posteriormente se le han agregado organismos como la OIE,

\footnotetext{
${ }^{53}$ Crítico con la falta de formación, capacitación y sensibilización de las unidades de policía y guardia civil VÁZQUEZ SALGADO, Inspector-Jefe de la Brigada de Policía Judicial de Santiago de Compostela ("Protocolos de actuación policial ante la violencia de género", en CASTILLEJO MANZANARES, T. (Dir.), CATALINA BENAVENTE, M.A. (Coord.), Violencia de género, justicia restaurativa y mediación, Wolters Kluwer, La Ley, Madrid, 2011, pág. 206.

${ }^{54}$ Así, entre otros, Instrucción 7/2016, de la Secretaría de Estado de Seguridad.

${ }^{55}$ VALERA, N., Feminismo para principiantes, op. cit., pág. 252.

${ }^{56}$ La Declaración sobre eliminación de la violencia contra la mujer ya obligaba a los Estados en su art. 4.c) a proceder con la debida diligencia a fin de prevenir, investigar y, conforme a la legislación nacional, castigar todo acto de violencia contra la mujer, ya se tratar de actor perpetrados por el Estado o por particulares. En concreto, la Recomendación General núm. 19 y 28 advirtió de la posibilidad de atribuir responsabilidad a los Estados en caso de omitir la adopción de medidas con diligencia debida para impedir, investigar, castigar y reparar la violencia contra la mujer.
} 
la CIDH, el Consejo de Europa y el TEDH. El que haya pasado a ser una obligación jurídica con trascendencia internacional trae causa en la desconfianza generada tras años de tratamiento sesgado y sin tener en consideración los roles sociales y culturales que abocaban a las mujeres a sufrir episodios de violencia para, posteriormente, pasar por la violencia institucional ${ }^{57}$. Afortunadamente, este estudio ha puesto de manifiesto que algunas de esas deficiencias han sido detectadas y se han puesto en marcha las medidas necesarias para su subsanación. No obstante, aún falta mucho por hacer, especialmente en la fase de ejecución de las resoluciones que determinan la responsabilidad de los Estados o de las Administraciones Públicas, como bien se ha podido ver con las emitidas por la CEDAW o el TEDH. Una normativa que su estricto carácter vinculante y obligatorio no va acompañado de un mecanismo de garantía de dicho cumplimiento difumina su contenido hasta diluirse, por lo que es en ese ámbito dónde han de concentrarse los esfuerzos.

La obligatoriedad en la ejecución de las sentencias del TEDH asumida por Tribunal Constitucional junto con la vinculación a las resoluciones de la CEDAW a la que aludía el Tribunal Supremo son muy esperanzadoras. En esta línea se puede caminar hacía el reforzamiento de lo que debe ser un sistema a la vanguardia del checks and balances en materia de derechos humanos. En definitiva, avanzar hacia lo que ya CARMONA CUENTA $^{58}$ preconizaba como un auténtico Ius Publicum Europeaum en materia de derechos y libertades, para lo que a su vez puede resultar muy útil la fertilización cruzada jurisprudencial con la $\mathrm{CIDH}^{59}$.

\section{BIBLIOGRAFÍA}

ACALE SÁNCHEZ, M., La discriminación hacia la mujer por razón de género en el Código penal, Reus, Madrid, 2006.

- “Aspectos penales del Pacto de Estado español contra la violencia de género", en Rivista di Diritto penale contemporaneo, núm. 1, 2018.

- Violencia sexual de género contra las mujeres adultas. Especial referencia a los delitos de agresión y abuso sexuales, Reus, Madrid, 2019.

\footnotetext{
${ }^{57}$ Esto de la violencia institucional por un inadecuado tratamiento de la violencia de género sucede hoy en día con el reconocimiento de derechos procesales a las víctimas, como la dispensa del deber de declarar. En este sentido, se ha discutido mucho sobre el alcance de la revictimización que en el proceso puede darse. Me detengo en la cuestión en DE LA HERRÁN RUIZ-MATEOS, S., "A vueltas con la dispensa del deber de declarar de las víctimas de violencia de género a propósito de la Sentencia del Tribunal Supremo 389/2020, de 10 de julio", en Revista de Derecho Penal y Criminología, núm. 23, 2020, págs. 45-66.

${ }^{58}$ CARMONA CUENCA, E., "La igualdad de género en el Tribunal Europeo de Derechos Humanos: un reconocimiento tardío con relación al Tribunal de Justicia de la Unión Europea”, op. cit., pág. 299.

59 Vid., MACULAN, Elena, "La fertilización cruzada jurisprudencial y los modelos de responsabilidad. Acordes y desacuerdos en la jurisprudencia latinoamericana", en op. cit., Dykinson, Madrid, 2013, págs. 69-144
} 
- "La reforma de los delitos contra la libertad sexual de mujeres adultas: una cuestión de género", en MONGE FERNÁNDEZ, A. (Dir.), PARRILLA VERGARA, J., (Coord.), Mujeres y Derecho: ¿necesidad de una reforma desde una perspectiva de género?, Bosch editor, Barcelona, 2020.

- "El consentimiento de la víctima: piedra angular en los delitos sexuales", en DÍAZ Y GARCÍA CONLLEDO, M., PAREDES CASTAÑÓN, J.M., OLAIZOLA NOGALES, I., TRAPERO BARREALES, M.A., ROSO CAÑADILLAS, Raquel, LOMBANA VILLALBA, J.A., (Dirs.), Libro homenaje al Profesor Diego Manuel Luzón Peña con motivo de su 70ªniversario, Reus, Madrid, 2020.

- "La visibilización de la violencia sexual como una modalidad de violencia de género", en BUSTOS RUBIO, M., ABADÍAS SELMA, A. (Dirs.), Una década de reformas penales: análisis de diez años en el Código Penal (2010-2020), Bosch, Barcelona, 2020.

CALDERÓN CAMBOA, J., RECINOS, J.D., "La perspectiva de género en casos de violencia sexual en conflicto armado: aportes de las Sentencias de la Corte IDH en los casos Las Masacres de las dos Erres Vs. Guatemala y Espinoza Gonzáles Vs. Perú", en PARRA VERA et al. (Eds.), La lucha por los Derechos Humanos hoy. Estudios en homenaje a Cecilia Medina Quiroga, Tirant lo Blanch, Valencia, 2017.

CARMONA CUENCA, E., "La igualdad de género en el Tribunal Europeo de Derechos Humanos: un reconocimiento tardío con relación al Tribunal de Justicia de la Unión Europea”, en Revista Española de Derecho Constitucional, núm. 104, 2015.

- "Los principales hitos jurisprudenciales del Tribunal Europeo de Derechos Humanos en materia de igualdad de género", en Revista de Teoría y Realidad Constitucional, núm. 42, 2018.

CARRILLO SALCEDO, J.A., Dignidad frente a barbarie. La Declaración Universal de los Derechos Humanos cincuenta años después, Trotta, Madrid, 1999.

CÁSTOR VÁZQUEZ SALGADO, J., "Protocolos de actuación policial ante la violencia de género", en CASTILLEJO MANZANARES, R. (Dir.), CATALINA BENAVENTE, M.A. (Coord.), Violencia de género, justicia restaurativa y mediación, Wolters Kluwer, La Ley, Madrid, 2011.

DE LA HERRÁN RUIZ-MATEOS, S., "A vueltas con la dispensa del deber de declarar de las víctimas de violencia de género a propósito de la Sentencia del Tribunal Supremo 389/2020, de 10 de julio”, en Revista de Derecho Penal y Criminología, núm. 23, 2020. 
- "La intervención estatal en la erradicación de la violencia contra las mujeres como un compromiso con los Derechos Humanos: el caso de España", en Revista Electrónica de Estudios Penales y de la Seguridad, núm. Especial 7, 2021.

DE LEÓN, Guisela, KRSTICEVIC, V., OBANDO, L., Debida diligencia en la Investigación de Graves Violaciones a Derechos Humanos, CEJIL, Argentina, 2010.

EDWARS, A., Violence against women under International Human Rights Law, Cambridge University Press, 2011.

FERNÁNDEZ, E., Igualdad y Derechos Humanos, Tecnos, M., 2003.

GIL RUIZ, J.M. (Dir.), VV.AA., El Convenio de Estambul como marco de derecho antisubordiscriminación, Dykinson, Madrid, 2018.

GÓMEZ RESTREPO, A., HERRERA TOVAR, D.F., "La debida diligencia judicial y la protección de los derechos humanos de las mujeres en contextos de violencia", en Revista Iustitua, núm. 16, 2018.

GUTIÉRREZ ESPADA, C., "La aplicación en España de los dictámenes de los comités internacionales: la STS 1263/2018, un importante punto de inflexión”, Cuadernos de Derecho Transnacional, 2018, vol. 10-2.

HERNÁNDEZ LLINÁS, L., "Hijos e hijas de la mujer maltratada como víctimas de la violencia de género: el caso González Carreño contra España y la STS 1263/2018”, en DEL POZO PÉREZ, M. (Dir.), BUJOSA VADELL, L. (Dir.), GONZÁLEZ MONJE, A. (Coord.), Proceso penal y víctimas especialmente vulnerables. Aspectos interdisciplinares, Aranzadi, Navarra, 2019.

LAURENZO COPELLO, P., “La discriminación en el Código penal de 1995”, en Revista de Estudios Penales y Criminológicos, XIX, 1996.

- "La discriminación por razón de sexo en la legislación penal", en Revista de Jueces para la Democracia, núm. 34, 1999.

LÓPEZ-JAICOSTE DÍAZ, E., "Violencia doméstica y malos tratos en el Tribunal Europeo de Derechos Humanos", en Anuario Español de Derecho Internacional, vol. XXV, 2009.

LOUSADA AROCHENA, J.F., "Encuentros y desencuentros entre el TEDH y el TJUE en materia de igualdad de género", en Femeris, vol. 4, núm. 2, 2019.

LOZANO CONTRETAS, J.F., La noción de debida diligencia en Derecho internacional público, Atelier, Barcelona, 2007. 
MACULAN, E., "La fertilización cruzada jurisprudencial y los modelos de responsabilidad. Acordes y desacuerdos en la jurisprudencia latinoamericana", en GIL GIL, >., (Dir.), MACULAN, E., (Coord.), Intervención delictiva y derecho penal internacional: reglas de atribución de la responsabilidad en crímenes internacional, Dykinson, Madrid, 2013.

MANGAS MARTÍN, A., LIÑAN NOGUERAS, D.J., Instituciones y Derecho de la Unión Europea, Tecnos, Madrid, 2015.

MAQUEDA ABREU, M.L., "La violencia de género. Entre el concepto jurídico y la realidad social", en Revista Electrónica de Ciencia Penal y Criminología, 08-02, 2006.

MARTÍNEZ VARGAS, J.R., VEGA BARBOSA, G., "La obligación estatal de prevención a la luz del corpus iuris internacional de protección de la mujer contra la violencia de género", en Revista Ius et Praxis, núm. 2, 2019.

MESTRE CHUST, J.V., Los derechos humanos, UOC, Barcelona, 2007.

VALERA, N., Feminismo para principiantes, Peguin Random, Barcelona, 2019.

VILLACAMPA ESTIARTE, C., "La protección de las víctimas en el proceso penal: consideraciones generales e instrumentos de protección", en TAMARIT SUMALLA, J.M. (Coord.), El estatuto de las víctimas de delitos: comentario a la Ley 4/2015, Tirant lo Blanch, Valencia, 2015.

VOLGELFANGER, A.D., "El deber de prevención en casos de violencia de género: desde «Campo Algodonero» hasta «Veliz Franco»", en Eunomía, Revista en Cultura de la Legalidad, núm. 9, octubre 2015 - marzo 2016. 